\title{
"Zonas de não ser":
mulheres negras sem-teto
e deslocamento
nos Estados Unidos
} "Zones of Non-Being": Black Women, Homelessness and
Displacement in the United States

Christen A. Smith* Michaela Machicote**

\begin{abstract}
Resumo - As mulheres negras, silenciadas, invisíveis e pobres da classe trabalhadora lutam apenas para sobreviver em Austin, Texas, nos EUA. Este artigo argumenta que as experiências das mulheres negras sem-teto e a discriminação habitacional nos Estados Unidos indicam que a gentrificação não é apenas um processo social limitante, mas também mortal. Existe uma relação nítida, porém implícita, entre gentrificação e supremacia branca patriarcal estrutural e interpessoal. Esse processo racializado de renovação da cidade também tem um gênero agudo. Existe uma relação dialética entre gentrificação e apagamento específico de mulheres negras do espaço público. Em nenhum lugar isso é mais evidente do que nas experiências das mulheres negras sem-teto. Essas mulheres em Austin ocupam uma "zona de não-ser", em que não têm direitos à cidade, ao espaço territorial doméstico e pouco ou nenhum ao acesso a serviços sociais. Palavras-chave: mulheres negras; sem-teto; discriminação habitacional; Estados Unidos; gentrificação.
\end{abstract}

\begin{abstract}
Silenced, invisible, and poor, working-class black women struggle just to survive in Austin, Texas, EUA. This article argues that Black women's experiences with homelessness and housing discrimination in the United States indicate that gentrification is not only a limiting social process but also a deadly one. There is a clear yet implicit relationship between gentrification and structural and interpersonal patriarchal white supremacy. This racialized process of "urban renewal" is also acutely gendered. There is a dialectical relationship between gentrification and the specific erasure of black women from public space. Nowhere is this more evident than with black women's experiences with homelessness. Black homeless women in Austin occupy a, "zone of nonbeing" in which they have no rights to the city, no territorial home space and little to no access to social services. Keywords: black women; homelessness; housing discrimination; United States; gentrification.
\end{abstract}

\footnotetext{
* Ph.D. É professora associada dos Departamentos de Estudos da África e da Diáspora Africana e Antropologia na Universidade do Texas, Austin. E-mail: christen.smith@austin.utexas.edu. ORCID: https://orcid.org/0000-0003-06707907.

** M. A. É mestre em estudos latino-americanos pelo Instituto Lozano Long de Estudos Latino-Americanos na Universidade do Texas, em Austin, e atualmente é doutoranda no Departamento de Estudos da África e da Diáspora Africana. E-mail: mmachicote@gmail.com. ORCID: https://orcid.org/0000-0003-0767-8714.
} 


\section{Revilgtg am Pollt}

\} "ZONAS DE NÃO SER" - SMITH, C.; MACHICOTE, M. \}

DOI: $10.12957 /$ REP.2020.52017

A cidade norte-americana de Austin, Texas, é celebrada como a "capital mundial da música ao vivo" e tem uma das maiores taxas de crescimento de população nos Estados Unidos. No entanto, o crescimento e a popularidade da cidade acompanharam um declínio exponencial no que se refere à população negra, bem como houve apagamento de espaços, cultura e pessoas negras do cenário urbano (TANG, 2014). Esse processo racializado de renovação também tem um recorte agudo de gênero. Existe uma relação dialética entre gentrificação e apagamento específico de muIheres negras do espaço público. Em nenhum lugar isso é mais evidente do que nas experiências das mulheres negras sem-teto. Essas mulheres em Austin ocupam uma "zona de não ser", em que não têm direitos à cidade, ao espaço territorial doméstico e pouco ou nenhum acesso a serviços sociais. ${ }^{1}$

Políticas de discriminação e privação de direitos erguem uma série de obstáculos que impedem que as mulheres negras acessem a assistência habitacional do Estado, definindo assim os contornos da cidadania e do pertencimento espacial. As políticas de pertencimento são territorializadas por quem tem acesso à cidade, sobre quais espaços e sob que circunstâncias. Baseado em dois anos de pesquisa etnográfica sobre mulheres negras e violência em Austin, este ensaio examina a situação das mulheres negras em situação de rua em uma cidade que se define por sua inexistência.

Moses é a recepcionista num abrigo para sem-teto em Austin. Sua posição requer conhecimento completo das operações e serviços diários disponíveis no abrigo, além de um comportamento agradável e uma força profunda para encarar as histórias que ela ouve e as coisas que experimenta. Moses vai além de seus deveres quando se trata de mulheres e famílias no abrigo, e conhece os papéis de todos os membros da equipe:

Bem, você tem uma família negra que tem quatro e seis filhos, eles precisam passar por a, b, c, d até z [para se qualificar para programas de moradia e emprego], mas você tem uma pessoa branca que entra que talvez tenha um filho com algum tipo de deficiência. Eles pegam essa renda e dizem: tudo bem, você se qualifica e pode entrar nesse programa. Nós vamos pagar por um ano, talvez até cinco anos, por mais que exija e colocar você numa casa e fazer todas essas coisas. Mas a mulher, a garota negra com quatro e cinco filhos, ela tem que ter um emprego. Ela também pode ter um filho com deficiência, mas precisa ter um emprego. Ela tem que fazer tudo isso extra. Temos que relatar tudo, é tudo isso extra que precisa ser feito para que ela se qualifique. (Moses).

Moses acredita que os serviços não são concedidos a famílias negras, especificamente mães negras, por discriminação racial. Os responsáveis discriminam ativamente as mulheres negras quando procuram serviços para

\footnotetext{
${ }^{1}$ Nosso uso da frase "zona do não ser" segue o trabalho de Frantz Fanon e será discutido mais abaixo neste ensaio (FANON, 1963, 1968; MBEMBE, 2003, 2017).
} 


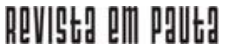

\} "ZONAS DE NÃO SER" - SMITH, C.; MACHICOTE, M. \}

DOI: $10.12957 /$ REP.2020.52017

si e suas famílias no abrigo. Ela se candidatou a um cargo de gerenciamento de casos mais de uma vez e foi negada. Ao especular sobre os motivos, ela conclui que é provavelmente uma combinação de discriminação racial, envelhecimento e o fato de o abrigo não valorizar seus 15 anos ou mais de trabalho para organizações sem fins lucrativos dedicadas a abrigos/abrigos de emergência, em vez do diploma de bacharel exigido. Segundo Moses, os contratados são geralmente jovens mulheres brancas, com um diploma de bacharel e pouca ou nenhuma experiência anterior, o que significa que precisam de treinamento - algo que Moses também poderia receber se o abrigo escolhesse investir nela.

Se as mulheres negras ocupam uma posição marginalizada nos Estados Unidos, as mulheres negras sem-teto vivem à beira da precariedade, e em Austin isso significa extrema periferização e invisibilidade. A falta de sistemas de apoio para atender às necessidades específicas das mulheres negras e os obstáculos estruturais que inibem essas mulheres, que buscam serviços de habitação, para obterem esses serviços impedem que elas sejam incluídas no cenário social da cidade: gentrificação + discriminação racial de gênero = privação de direitos espacial. Fatores econômicos, como desemprego, subemprego, altos custos habitacionais, falta de apoio e redes familiares, serviços de saúde mental sucateados, suporte inadequado de serviços sociais, falta de moradia, acesso precário à educação e hipercriminalização criam a tempestade perfeita que empurra as mulheres negras ao que Frantz Fanon (1963) chamou de "zona do não ser".

Os antropólogos que estudam os sem-teto analisam as maneiras como essas pessoas recusam a territorialização de seus corpos e, por consequência, experimentam a alienação nos espaços urbanos (COOPER, 2018; O'NEILL, 2014). No entanto, poucos examinam o impacto específico da falta de moradia nas mulheres negras (COX, 2015). Os estereótipos antigos caracterizam as mulheres negras norte-americanas sem-teto como mães impróprias, preguiçosas e não merecedoras de políticas assistenciais, classificando-as de "rainhas dos serviços sociais" ("welfare queens"), impedindo que mulheres negras pobres tenham acesso à educação e assistência social. ${ }^{2}$ Estes estereótipos se tornaram parte do discurso racial e hegemônico de moradia, inclusão e exclusão, remodelando a forma como a precariedade e a territorialidade econômicas são vividas e experimentadas. Como consequência, existe uma discriminação generalizada contra as mulheres negras que buscam assistência habitacional em lugares como Austin, especialmente no que diz respeito aos sem-teto.

As estatísticas mostram que $73 \%$ das pessoas em abrigos para semteto em Austin são mulheres e crianças (SALVATION ARMY, 2016) e 42\% da população sem-teto de Austin é negra, apesar de apenas 8\% da população

2 Para uma discussão robusta sobre as maneiras pelas quais "imagens controladoras" - tipografias estereotipadas de mulheres negras - moldam o acesso das mulheres negras a recursos e uma vida plena, veja, por exemplo, Collins (1991) e Spillers (1987). 


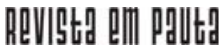

\} "ZONAS DE NÃO SER" - SMITH, C.; MACHICOTE, M. \}

DOI: $10.12957 /$ REP.2020.52017

geral da cidade ser negra (ECHO, 2017). Pesquisas sobre disparidade econômica racializada e de gênero em Austin são praticamente inexistentes; no entanto, um estudo nomeou Austin como uma das áreas metropolitanas mais segregadas por renda nos Estados Unidos (FLORIDA; MELLANDER, 2017). A medida que a cidade cresce rapidamente e se torna cada vez mais gentrificada, as mulheres negras estão sendo expulsas espacial e simbolicamente.

\section{Metodologia}

Este artigo é baseado em dois anos de pesquisa etnográfica sobre violência contra mulheres negras em Austin, Texas. É apenas um aspecto de um projeto de pesquisa etnográfica maior sobre as experiências de muIheres negras com violência em Austin, em que realizamos 21 entrevistas qualitativas, quatro grupos focais e 49 pesquisas com mulheres negras estudando e/ou trabalhando em universidades, vivendo em precariedade econômica e navegando na política de não conformidade de gênero em toda a cidade. Como parte desse projeto, realizamos pesquisas etnográficas em abrigos para moradores de rua, que incluíam observação participante e colaboração comunitária. Este ensaio focaliza nossas descobertas em muIheres negras que sofrem precariedade econômica.

Nossa abordagem metodológica é informada criticamente pela antropologia feminista negra (CALDWELL, 2007; DAVIS, 2006; MCCLAURIN, 2001; MULLINGS, 1997; PERRY, 2013; WILLIAMS, 2013; 2018). As antropólogas feministas negras fizeram uma extensa pesquisa sobre as dimensões interculturais e socioculturais do racismo de gênero na vida das mulheres negras. O que emergiu de nosso trabalho etnográfico foi uma série de informações importantes sobre a relação entre exclusão espacial e violência na vida de mulheres negras. Logo, descobrimos que a moradia era um dos temas mais importantes que se repetiam quando as mulheres negras compartilhavam suas experiências com a violência. Nesse sentido, a violência estrutural é uma das formas mais agudas de violência que as mulheres negras experimentam em Austin.

\section{Hiper(in)visível: mulher negra, segregação e exclusão em Austin}

\footnotetext{
"Geografias físicas estão enredadas com processos sociais"
} (Katherine McKittrick, Demonic Grounds)

Austin é sede de centenas de festivais de música, possui grandes empresas de tecnologia, uma grande universidade pública e uma pequena universidade privada, e é uma população construída em torno de uma 


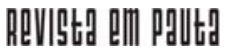

\} "ZONAS DE NÃO SER" - SMITH, C.; MACHICOTE, M. \}

DOI: $10.12957 /$ REP.2020.52017

personalidade jovem, vibrante e promissora. Também é conhecida como um pontinho "azul" que apoia o partido democrático, considerado mais liberal, na vasta paisagem "vermelha" do Texas que apoia o partido republicano, considerado mais conservador. No entanto, o status da moda de Austin também tem um ventre inglório: gentrificação. Os custos de habitação dispararam nas últimas duas décadas. Esse aumento nos custos de moradia teve um efeito adverso na população negra dessa cidade. Embora Austin tenha sido "classificada constantemente entre as principais cidades que mais crescem nos Estados Unidos", nos últimos vinte anos, sua população negra está diminuindo rapidamente - tanto que em 2014 foi "a única cidade importante dos Estados Unidos a experimentar uma taxa de dois dígitos do crescimento da população em geral, coincidente com o declínio da população afro-americana" (TANG e FALOLA, 2016, p. 2).

A geógrafa cultural Katherine McKittrick (2006, p. 67-68) argumenta que "as geografias físicas estão enredadas em processos sociais". Em Austin, o processo social de gentrificação não é um fenômeno recente, mas que pode ser ligado genealogicamente à dura história da segregação racial na cidade. ${ }^{3}$ No período após a abolição "legal" da escravidão, em cerca de 1869 a 1930, o lado leste de Austin foi colonizado principalmente por afro-americanos que criaram enclaves comunitários movimentados, apesar de pequenos, e com uma cultura comercial vibrante (TANG 2014; TANG e FALOLA, 2016). Havia também algumas áreas do lado oeste - a região agora habitada pela classe média alta e principalmente por brancos - que foram colonizadas por moradores negros, principalmente o bairro de Clarksville, da rua West Lynn a Mopac, no final do século XIX.

Em 1928, as práticas raciais informais de segregação se tornaram um aspecto formalizado do planejamento da cidade. Naquele ano, a cidade criou oficialmente um "distrito Negro" e planejou remover residentes negros de seus bairros restantes no lado oeste da cidade e realocá-los para o lado leste (HOUSTON, 2018). A cidade desenvolveu o "distrito Negro" a leste do Capitólio do Texas e atraiu afro-americanos para o lado leste, colocando todas as escolas e parques segregados designados para afro-americanos neste novo distrito. A população latina de Austin logo seguiu esse movimento, estabelecendo-se na parte sudeste da cidade, logo abaixo da parte afroamericana da cidade.

Por gerações, o lado leste de Austin era conhecido como uma área principalmente negra e latina da cidade e, portanto, era negligenciada e criminalizada. Depois que Austin começou a se expandir, e a necessidade de morar no centro da cidade aumentou, o lado leste se tornou o novo local "quente" para se mudar para funcionários de alta tecnologia e outros jovens, principalmente brancos, homens e mulheres de negócios. Esse

\footnotetext{
${ }^{3}$ O relatório de 2017 , intitulado Força-tarefa do prefeito sobre racismo institucional e desigualdades sistêmicas, fornece uma visão geral da história da segregação de jure e de fato em Austin.
} 


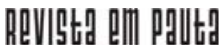

\} "ZONAS DE NÃO SER" - SMITH, C.; MACHICOTE, M. \}

DOI: $10.12957 /$ REP.2020.52017

afluxo de residentes novos e com dinheiro elevado aumentou os valores e os impostos sobre a propriedade na área, levando muitos residentes negros e latinos a sair - e contribuindo fortemente para o declínio da população negra (TANG e FALOLA, 2016). Tang e Falola (2016) descobriram que os moradores deixaram Austin para subúrbios próximos ao norte e leste da cidade, como Pflugerville e Manor. No entanto, essas áreas suburbanas são amplamente isoladas do núcleo urbano, carecem de serviços confiáveis de transporte e acesso a serviços de saúde. Lugares como Manor também são conhecidos como "desertos alimentares" (DSHS; COUNTY, 2011).

O deslocamento físico e econômico fez com que a pequena população negra de Austin se sentisse indesejada, desconfortável e hiper(in)visível na cidade. Uma das nossas entrevistadas, Sharon, administradora na universidade e moradora de Austin de longa data, resumiu esse sentimento em uma de nossas conversas. Ela testemunhou mudanças drásticas na demografia de Austin e um aumento de atitudes discriminatórias em relação às mulheres negras ao longo dos anos. Quando perguntada sobre o que significava ser uma mulher negra em Austin, ela respondeu:

Ser uma mulher negra em Austin é ser invisível de várias maneiras, a menos que você seja interpretada como tendo se comportado mal, esse tipo de coisa, a menos que você tenha feito algo, tipo, errado, criminoso, ou conectado a esportes, ou você é conectada a alguém, sabe, num relacionamento. Mas acho que ser uma mulher negra em Austin, como ser uma mulher negra em qualquer lugar, até ser mulher independente de raça, tudo está conectado aos nossos relacionamentos com todo o resto, apenas a nós. Sinto que nossos problemas e preocupações são ignorados e não são valorizados, sim, estamos definitivamente marginalizadas. (Sharon).

Devemos muito do conhecimento que temos sobre a história de Austin à nossa entrevista com Sharon. Sua família vive em Austin há gerações e ela trabalha em estreita colaboração com a comunidade afro-americana circundante, inclusive trabalhando para preservar a herança e a memória das comunidades negras do lado oeste que agora são apagadas há muito tempo.

O deslocamento da comunidade negra de Austin significou o apagamento simultâneo de mulheres negras do imaginário social e a demonização de mulheres negras na imaginação popular: mulheres negras são invisíveis até serem difamadas. Como consequência, as mulheres negras sofrem em silêncio, principalmente quando não têm recursos econômicos para partir para os subúrbios ou criar redes de segurança nos bolsos restantes da comunidade negra da cidade. De acordo com Sharon, mesmo as organizações intracomunitárias especificamente para negros - que, com certeza, também estão sob ameaça iminente - se envolvem em discriminação de classe, aceitando apenas aqueles negros que se enquadram nos padrões da classe média. 


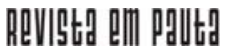

\} "ZONAS DE NÃO SER" - SMITH, C.; MACHICOTE, M. \}

DOI: $10.12957 /$ REP.2020.52017

Essas organizações são para um certo tipo de mulher negra, e eu cresci com essa mulher negra. Quero dizer, eu participei, sabe, que eu era uma debutante, e todas essas coisas, mas se você não é cristã, heterossexual, de classe média a alta, sabe, esteticamente parece de uma certa maneira, cor e tudo, elas não são, não são para você, então eu me sinto um pouco consciente demais para não tirar do meu povo. (Sharon).

As mulheres negras, silenciadas, invisíveis e pobres da classe trabaIhadora lutam apenas para sobreviver em Austin. As mulheres negras com quem trabalhamos expressaram uma "falta de recursos para mulheres negras" em Austin. Existem poucas organizações nesta cidade especificamente para pessoas negras. Muitas vezes, as organizações comunitárias são voltadas para "pessoas de cor", o termo genérico para quem não é branco. No entanto, a consequência irônica dessa inclusão é que os negros são excluídos à custa da inclusão de outras pessoas de cor que são mais palatáveis de acordo com o éthos cultural de Austin, que adere à lógica da supremacia branca.

A hiper(in)visibilização torna todos os negros suscetíveis a uma matriz de violência, desde a violência estrutural da discriminação habitacional, passando pelas microagressões interpessoais de não negros, até a violência policial. ${ }^{4}$ Essa matriz de violência é complexa e interconectada uma forma de violência direta ou indiretamente se alimenta de outra. Por exemplo, em 2015, a professora do ensino fundamental Breaion King recebeu brutalmente uma pancada corporal do policial Brian Richter, do Departamento de Polícia de Austin (APD), durante uma parada de trânsito de rotina.

Em Austin, o termo "mulher negra" é realmente uma codificação telegráfica - carregada com a possessão mítica de não pertencer, com a invisibilidade, com abjeção e "tendências violentas" na imaginação popular da cidade. Ser mulher negra em Austin é ser aquilo que não pode ser visto e o que deve ser eliminado. Uma "síntese de opressões" que inclui racismo, sexismo, heterossexismo e classismo, "cria as condições de nossas vidas" (COMBAHEE RIVER COLLECTIVE 1977).

Segundo as geógrafas feministas Kobayashi e Peake (1994), raça e gênero foram construídos como fenômenos naturais e não culturais. A filosofia geográfica ocidental tem sido cúmplice nessa naturalização ao extrair do discurso duradouro sobre o lluminismo e seu objetivo de colocar "o mundo dentro de uma ordem ideológica, criando ambientes de acordo com categorias socialmente construídas e naturalizadas [...], transformando a superfície da terra na imagem de um homem [branco]" (KOBAYASHI; PEAKE, 1994, p. 227). Isso levou ao "pensamento dualista", um processo que organiza o mundo de acordo com binários que servem para manter o

${ }^{4}$ A frase "matriz da violência" é usada pela socióloga Patricia Hill Collins (1991) para definir as experiências cotidianas das mulheres negras nos Estados Unidos. 


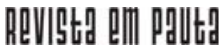

\} "ZONAS DE NÃO SER" - SMITH, C.; MACHICOTE, M. \}

DOI: $10.12957 /$ REP.2020.52017

poder político e o privilégio de uma coisa sobre a outra (KOBAYASHI; PEAKE, 1994, p. 227). A organização de nosso espaço urbano nos Estados Unidos foi incentivada pelas noções iluministas de quem é dono de que ou quem, e de quais corpos pertencem a quais espaços. Por sua vez, isso naturaliza os conceitos de público e privado, a separação por gênero e a separação geográfica.

\section{Empurradas para fora: mulheres negras, deslocamento e falta de moradia}

Um grande edifício de tijolos fica no centro de Austin, em frente a uma delegacia, a uma quadra de vários prédios do tribunal, no meio de uma das seções mais movimentadas da cidade. Quando você caminha até o prédio em um determinado dia, dificilmente parece habitado. Raramente alguém está do lado de fora do prédio, exceto trabalhadores ocasionais ou seguranças. Parece quieto e abandonado, mesmo quando se entra pelas portas da frente. Uma assistente administrativa fica na recepção para cumprimentar quem entra. É uma sala de espera estéril, muito parecida com o próprio prédio. Essa é a atmosfera dos abrigos para mulheres e familiares em Austin.

O abrigo para as mulheres parece intocado. Ninguém fica na frente. Há pouco lixo, e o segurança sempre vigia. As pessoas que residem lá vão e vêm como fantasmas. Subindo as escadas para a entrada da frente, se enfrenta o primeiro conjunto de portas. Essa entrada ostenta um detector de metais que raramente foi usado. Depois do segundo conjunto de portas, fica a mesa da recepção, com o que parece ser de plástico grosso, para que os clientes falem com a recepcionista através de um pequeno orifício na parede e passem a papelada pela fenda aberta, onde a partição plástica alcança a mesa. Ali, de frente para a área de recepção aberta, está Moses.

Raça, gênero, classe e sexualidade são lentes interseccionais críticas para entender a geografia e a identidade, particularmente a relação das mulheres negras com o espaço e o lugar (MCKITTRICK, 2006). As mulheres negras em Austin, especialmente as de baixa renda, acham difícil localizar e garantir moradias seguras e alcançáveis financeiramente. Um dos principais fatores que levam à falta de moradia é a discriminação habitacional, principalmente em residências designadas para indivíduos e famílias trabalhadores e de baixa renda.

Raina é uma mulher negra que morava no abrigo, e foi através de Moses que a conhecemos. Conversamos abertamente, e Raina ofereceu muitos detalhes sobre a violência que sofreu com agressões sexuais, em relacionamentos com homens muito mais velhos na adolescência, com falta de redes familiares e com um ex-marido abusivo que engravidou sua prima de 13 anos. Ela veio para Austin depois que o furacão Harvey a 


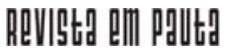

\} "ZONAS DE NÃO SER" - SMITH, C.; MACHICOTE, M. \}

DOI: $10.12957 /$ REP.2020.52017

deixou sem casa no sul do Texas, e o principal aspecto de sua entrevista se concentrava na discriminação no sistema de abrigos e no emprego, particularmente no quão difícil é apenas ser considerada para assistência à moradia e na impossibilidade de frequentar a escola:

Raina: Eu só estou vendo que eles se voltam mais para os mexicanos e os brancos nos empregos, como quando eu estava no abrigo, eles fazem mais por eles, a autoridade habitacional. Eu não conseguia nem morar e vim para cá como mãe solteira, por ficar sem casa, fiz a pequena coisa que eles fizeram e me disseram -

I: Avaliação?

Raina: avaliação! e eles me disseram que eu não era qualificado para moradia... eu perguntei [por que] e eles disseram 'bem, nós não sabemos o computador apenas faz isso.

Raina não vive mais no abrigo. Ela mora com seus filhos e os sustenta com a ajuda de seu parceiro. Ela descreve sua vida como uma mãe que fica em casa: "[está] relaxado, eu posso me exercitar, sentar em minha casa agora, todas as minhas contas são pagas e são pagas por meses, eu não preciso me preocupar com eles, estou confortável, não preciso me preocupar com meus filhos nas ruas". Antes, ela estava lutando com uma posição de salário mínimo em uma loja de variedades local. Raina descreveu as atitudes raciais que encontrou das gerentes latinas que a supervisionavam, e quando ela protestava, elas conversavam com ela com condescendência, dizendo: "você não precisa explicar isso para ela, ela é negra". Os supervisores brancos também discriminaram potenciais novos contratados negros:

Um amigo meu, a filha dele vai para a faculdade aqui em Austin, e ela ficava tipo 'eu quero trabalhar onde você trabalha, vocês estão contratando?' E eu fiquei tipo sim, estamos contratando, nós realmente precisamos de pessoas e depois ela entrou e eu a apresentei e disse que essa é a garota que se candidatou, ele a contratou e voltou e disse que não vou contratar sua família inteira. (Raina).

Para as mulheres negras que procuram assistência habitacional, a exigência de trabalhar para acessar os serviços habitacionais é muitas vezes complicada pela discriminação no emprego. Não apenas as mulheres negras são discriminadas nas práticas de contratação, mas também as muIheres sem-teto acham difícil obter o nível de educação necessário para se qualificar para alguns empregos quando são forçadas a trabalhar para se qualificarem para moradia. Isso é ainda mais complexo para moradoras de rua que são mães, que precisam trabalhar e cuidar das crianças. Mães desabrigadas negras e mães negras que buscam assistência econômica por moradia não podem se matricular nas aulas sem correr o risco de perder a assistência habitacional. Além disso, muitas mães negras acham difícil encontrar um apartamento acessível financeiramente quando têm vários filhos. 


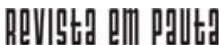

\} "ZONAS DE NÃO SER" - SMITH, C.; MACHICOTE, M. \}

DOI: $10.12957 /$ REP.2020.52017

Os complexos de apartamentos forçam ativamente as famílias monoparentais de vários filhos a alugar apartamentos de 2 a 3 quartos, que ficam fora do seu orçamento.

Então isso acontece regularmente... se eles quiserem ir à escola e continuar seus estudos, você não poderá fazer isso no abrigo se for negra, porque precisa trabalhar e sair, porque você tem apenas 90 dias para estar aqui. Então, em Austin, o custo de vida é tão alto para uma mãe solteira com quatro ou cinco filhos, é difícil trabalhar e cuidar melhor da sua casa. E nem isso, mas também tentando encontrar um apartamento que você pode pagar quando tem tantos filhos, e eles querem dizer, você sabe, você não pode ter tantos filhos neste apartamento. Se você precisa de dois, três quartos, mas isso é mais de mil dólares. Você não pode fazer isso. E nem pense em ter um contrato quebrado ou antecedentes criminais ou, você sabe, não venha com barreiras extras. Né. Sabe, isso vai causar alguns problemas para você conseguir entrar. (Moses).

As barreiras construídas para inibir as mulheres negras de acessar serviços de moradia em Austin refletem tanto a discriminação estrutural quanto a interpessoal. As mulheres negras que residem em abrigos para sem-teto em Austin são desencorajadas a se qualificar para assistência pública pelas atitudes dos gerentes de caso e pelas avaliações aparentemente intransponíveis pelas quais devem passar para serem consideradas dignas de ajuda. As mulheres negras não apenas são explicitamente discriminadas quando procuram moradia, mas também são implicitamente discriminadas quando são obrigadas a cumprir padrões difíceis ou impossíveis de alcançar.

Mariah tem 64 anos, vive com uma deficiência e é auxiliar de saúde em Austin, mas vive em um abrigo. Ela ensinou em uma escola pública em Nova Jersey por dez anos e depois se mudou para Austin aos 30 anos, porque sua mãe e seu pai se mudaram para lá e ela queria ficar perto deles. Seus pais moram em Austin há mais de 25 anos. Mariah estava na lista de moradias da seção 8 (um programa de moradia subsidiada) e, quando recebeu uma carta informando sua posição na lista, pensou que seria transferida para moradias imediatamente. Ela optou por não renovar seu contrato porque pensava que seria colocada em assistência habitacional; consequentemente, acabou no abrigo. Ela sente que, como mulher negra, "tem que estar consciente de quem eu sou em todos os momentos, porque as pessoas fazem você sentir que você é inferior - e eu nunca me senti inferior!".

Ser mulher negra em Austin, bem, não tem sido fácil, porque, embora haja muitas pessoas negras aqui, há muito mais outras cores. E eu os vi em alguns lugares, enquanto as mulheres negras não. Como em alguns trabalhos, há (voz baixa) mais mexicanos, e eles parecem ser os responsáveis, ou brancos. É difícil conseguir empregos, porque eles querem aquelas pessoas lá [...]. Esta é uma cidade rica, eles não querem pessoas pobres aqui... é uma cidade republicana. Eles querem 


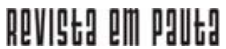

\} "ZONAS DE NÃO SER" - SMITH, C.; MACHICOTE, M. \}

DOI: $10.12957 /$ REP.2020.52017

pessoas aqui que têm dinheiro... Tudo aqui embaixo está começando a crescer. Eles estão construindo mais e mais hotéis. Podemos pagar para morar em um hotel? Mal podemos comprar estacionamento por aqui. Cada ano o aluguel aumenta. Não há nada que você possa fazer sobre isso. Eles não ajudam as pessoas quando precisam de ajuda. Se uma pessoa fica atrasada no aluguel e pede ajuda, três meses precisa esperar. Se eu tivesse três meses, não iria até você! Agora, estou nessa situação. Estou morando no [abrigo]. (Mariah).

Mariah repete as observações de Raina sobre as mulheres latinas serem escolhidas ou promovidas por serviços e empregos em detrimento das mulheres negras. O que as mulheres negras experimentam em Austin é mais complexo que o racismo: é uma atitude antimulher negra. Nossas suposições populares sobre o racismo tendem a reduzi-lo à discriminação interpessoal, que vem principalmente de brancos contra pessoas de cor de forma abrangente. Por esse motivo, o termo antimulher negra é útil. As experiências das mulheres negras em Austin revelam que existe um preconceito específico contra os negros na cidade que não se aplica a todas as pessoas de cor. De fato, as experiências de Raina e Mariah destacam a discriminação especificamente de residentes latinos. Isso nos leva de volta aos comentários de Sharon sobre serviços para pessoas de cor na cidade. Se prescrevermos que o racismo é a principal questão que inibe a capacidade das mulheres negras para uma vida plena em Austin, os serviços que visam principalmente às pessoas de cor seriam um mecanismo antirracista razoável para remediar esse problema.

O abrigo para os sem-teto serve como um aparato estatal que mantém as mulheres negras em precariedade econômica, valorizando apenas certos tipos de trabalho como produtivos. As mulheres negras têm acesso rotineiramente negado a programas e benefícios que ajudariam em seu caminho para a autossuficiência econômica. Seus pedidos são ignorados e as trabalhadoras não consideram que essas mulheres saibam ou tenham uma ideia de quais serviços as ajudariam a longo prazo. Além disso, a disparidade entre o número de mulheres negras e as famílias alojadas no abrigo e os gerentes de casos negros agrava práticas discriminatórias, deixando praticamente ninguém para intervir em nome dessas mulheres. Isso leva a sentimentos de desespero, raiva e humilhação. A falta de recursos de moradia e emprego, bem como as práticas discriminatórias por gerentes de casos, afetam o bem-estar emocional de mulheres negras que procuram serviços de moradias e trabalham na administração dessas habitações, como Moses. Moses descreve ser profundamente afetada pela discriminação que ela testemunha: "Bem, isso me afeta muito. Alguns dias eu chego ao trabalho e fico, bem, não posso mais trabalhar aqui, quero deixar esse emprego. E então, mas eu amo meu povo e quero ajudá-lo, sabe?" A violência estrutural que impede as mulheres negras de terem acesso à moradia também afeta as mulheres forçadas a testemunhar esse ciclo repetido de violência. 


\section{Uma zona de não ser: mulheres negras como "sujeitos deportáveis"}

As mulheres negras em Austin ocupam uma zona de não ser empurradas para fora da paisagem física e social através de processos de abjeção. Abjeção não é apenas a ação de expulsar ou abater, mas a condição de ser abatida, que é a condição de ser abjeta. Nesse sentido, a abjeção nos permite pensar em formas de violência e exclusão social não apenas em termos dos espaços aos quais estamos relegadas, mas também das subjetividades (ou falta delas) que ela produz. A discriminação habitacional empurra as mulheres negras para fora dos limites territoriais conceituais de pertencimento.

A frase de Frantz Fanon (1968) "zona do não ser" descreve a divisão maniqueísta entre os espaços do colonizador e o colonizado no contexto de assentamentos coloniais na África, Ásia e nas Américas. Especificamente, ele observa como as condições da colonização relegam os colonizados à zona de não ser - um espaço de não humanidade que degrada aqueles que são colonizados, atribuindo-lhes os espaços territoriais com as piores condições físicas da colônia. Aqui, os colonizados são tratados como bestiais, enquanto os colonizadores desfrutam dos frutos da terra. Ele escreve:

A cidade dos colonos é uma cidade fortemente construída, toda feita de pedra e aço. É uma cidade bem iluminada; as ruas estão cobertas de asfalto e as latas de lixo engolem todos os restos, invisíveis, desconhecidos e pouco pensados... A cidade dos colonos é uma cidade de brancos, de estrangeiros. (FANON, 1963, p. 39).

Os processos de gentrificação, como o de colonização, dividem espacialmente Austin entre aqueles que são brancos e/ou permitidos a pertencer e aqueles que não são brancos e que não pertencem. Isso é tipificado pela exclusão de mulheres negras de moradias populares e abrigos para sem-teto. Ao discutir Gamboa de Baixo, Keisha-Khan Perry (2017, p. 21) emprega a noção de zona do não ser para descrever como "o entendimento coletivo da desumanidade negra predetermina a intenção do Estado de matar por meio de ações policiais violentas ou negação de bens e serviços sociais". A zona do não ser é um aparato estatal antimulher negra. O apagamento transnacional gradual de bairros negros das paisagens urbanas é um processo transtemporal e diaspórico (transespacial). É transtemporal no sentido de que emerge da genealogia do colonialismo, e transnacional pois, como observa Perry (2017), é um padrão sistemático de comportamento contra as comunidades e espaços urbanos negros no mundo inteiro.

A discriminação que as mulheres negras enfrentam ao procurar moradia sugere que a cidade de Austin imagina seus "cidadãos" (aqueles que pertencem e têm direito à cidade) como mulheres não negras. Além disso, essa narrativa (pertencer a Austin não é ser mulher negra) também é hegemônica, influenciando como a cidade em geral imagina e trata 


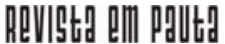

\} "ZONAS DE NÃO SER" - SMITH, C.; MACHICOTE, M. \}

DOI: $10.12957 /$ REP.2020.52017

mulheres negras, exemplificada pela discriminação de emprego praticada pelos gerentes latinos. Quando usamos o termo hiper(in)visibilidade para descrever como as mulheres negras são ignoradas, inéditas e tratadas em Austin, há uma referência à cidadania e ao pertencimento aqui também. As mulheres negras são "sujeitos deportáveis" dentro da cidade. ${ }^{5}$ Carole BoyceDavies (2008) argumenta que as mulheres negras nos Estados Unidos são sempre definidas como "sujeitos deportáveis" - aquelas que não pertencem, não têm acesso à cidadania e podem ser removidas a qualquer momento, independentemente de seu status legal de cidadania. Em outras palavras, "cidadania" é uma demarcação sociopolítica, e não uma denotação legal: a cidadania das mulheres negras é suspensa, reversível e condicional. Vale a pena citar as palavras de Davies (2008, p. 137),

A deportação, claramente o outro lado da imigração, também cria outra dimensão da diáspora. Uma construção diferente da diáspora, além da dialética do exílio em casa, mas com uma compreensão de uma variedade de comunidades interconectadas globalmente, revela algumas questões mais práticas. Reconhecimento de que alguém é sempre um 'sujeito deportável'.

Para Davies (2008), os afro-americanos ocupam a posição de colonizados dentro do Estado-Nação. ${ }^{6}$ Como consequência, estes não são cidadãos plenos, apesar de cumprirem todas as qualificações legais para a cidadania. Davies (2008, p. 145) escreve: "tecnicamente os Estados Unidos funciona como um 'estado multinacional', com os afro-americanos sendo tratados historicamente às vezes como equivalentes ou muitas vezes piores que os estrangeiros". Tecnicamente, os afro-americanos são sujeitos deportáveis porque, inerentemente, não pertencem como sujeitos do Estado-Nação, mas são vistos como objetos do Estado-Nação. E, embora pensemos na deportabilidade como algo ligado ao estrangeiro, também podemos vinculá-la conceitualmente a um fenômeno interno, intranacional, como a gentrificação - os negros são expulsos da cidadania nos níveis local e nacional.

Como observa Aimee Cox (2015, p. 41), "os medos e ansiedades do Estado-nação são projetados nas mulheres negras e atualizados através do controle discursivo e material de seus corpos". Antropólogos que examinaram a cidadania negra na diáspora africana observam que existem muitas lacunas conceituais nas maneiras como definimos e enquadramos a cidadania no mundo do Atlântico Negro (CLARKE, 2013, p. 465). A relação entre os negros e o Estado-Nação, bem como os processos de negociação

\footnotetext{
${ }^{5} \mathrm{O}$ trabalho de Jenn Jackson (2015) sobre Branquitude, compras e a (hiper)(in)visibilidade de mulheres negras referese à noção de ser vista e "tratada de maneira diferente por causa do corpo e da percepção da utilidade de servir à branquitude". Olivia Cole (2017) menciona esse estado de ser para crianças negras, falando sobre disparidades raciais no tratamento de crianças em idade escolar por figuras de autoridade.

"A noção de "colonialismo interno" foi desenvolvida por Pablo Gonzalez Casanova (1965) para descrever as tensões entre Estados-Nação e suas populações racializadas e marginalizadas internamente.
} 


\section{Revilgtg am Pollt}

\} "ZONAS DE NÃO SER" - SMITH, C.; MACHICOTE, M. \}

DOI: $10.12957 /$ REP.2020.52017

em que os negros se envolvem para navegar no pertencimento nacional, são difíceis e desiguais em todo o mundo (CLARKE e THOMAS, 2006; CLARKE, 2013; HARRISON 2008; PERRY, 2013; PIERRE, 2013; RAHIER, 2014; SMITH, 2015; THOMAS, 2004; THOMAS 2011; WILLIAMS, 2013). No entanto, consistentemente, descobrimos que a negritude está à margem do conceito de cidadania e pertencimento nacional, particularmente nas Américas. Isso se traduz nas experiências espaciais das mulheres negras dentro do Estado-Nação.

As geografias das mulheres negras estão em constante estado de deslocamento ${ }^{7}$ globalmente. Por esse motivo, etnógrafas e geógrafas feministas negras explicam o relacionamento das mulheres negras com o Estado e a cidadania como exclusão das mulheres negras da nação. Dentro de Austin, as dimensões socioespaciais do deslocamento se tornam cada vez mais aparentes. A periferalização não está sendo forçada apenas aos arredores da cidade. Como demonstramos com abrigos para sem-teto, as muIheres negras podem ser relegadas às margens, até mesmo a espaços liminares dentro do "centro" da cidade. As "posições periféricas e marginais localizam a maneira pela qual a identidade e a subjetividade podem politizar ausências, apagamentos e opressões" (MCKITTRICK, 2006, p. 55-56). Como McKittrick (2006), consideramos as mulheres negras investidas e especialistas na produção de geografias precisamente porque foram "imaginadas fora da produção do espaço" (MCKITTRICK, 2006, p. 54). Sua sobrevivência de espaçotempo incalculável e duradouro de violência racial-sexual também criou matéria generativa e autoritária. As mulheres negras que entrevistamos entendem a confluência de processos que levaram à sua condição em Austin.

Embora Austin seja um local de exclusão social e disparidade econômica que reifica a hierarquia racial e de gênero de homens e mulheres brancos, também é um local de resistência. É alterável. As mulheres negras politizam seu apagamento em Austin, criando espaços para si mesmas através de eventos comunitários, como exposição natural ao cabelo, comunidades online que planejam encontros, cúpulas para mulheres negras, corridas em Austin e expressão da arte performática na cidade. 


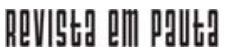

\} "ZONAS DE NÃO SER" - SMITH, C.; MACHICOTE, M. \}

DOI: $10.12957 /$ REP.2020.52017

\section{Referências}

CALDWELL, K. L. Negras in Brazil/ Re-Envisioning Black Women, Citizenship, and the Politics of Identity / Kia Lilly Caldwell. New Brunswick, N.J: Rutgers University Press, 2007.

CASANOVA, P.G. Internal Colonialism and National Development. Studies in Comparative International Development 1(4):27-37, 1965.

CLARKE, K. M. Notes on cultural citizenship in the Black Atlantic world. Cultural Anthropology, v. 28, n. 3, 2013.

CLARKE, K. M.; THOMAS, D. A. (Ed.). Globalization and race: transformations in the cultural production of blackness. Durham: Duke University Press, 2006.

COLE, O. McKinney, Texas and the Hypervisible Invisibility of Black Children. Huffpost Is Now A Part Of Verizon Media. [online] Huffpost.com, 2015. Disponível em: https://www.huffpost.com/entry/mckinney-texashypervisible-invisibility-black-children_b_7536426. Acesso em: 22 ago. 2018.

COLLINS, P., Black feminist thought. New York: Routledge, 1991.

COOPER, J. Unruly affects: attempts at control and all that escapes from an American mental health court. Cultural Anthropology, v. 33, n. 1, 2018.

COMBAHEE RIVER COLLECTIVE, Combahee River Collective Statement, 1977.

COX, A. M. Shapeshifters: black girls and the choreography of citizenship. Durham: Duke University Press, 2015.

DAVIES, C. Left of Karl Marx: The Political Life of Black Communist Claudia Jones. Duke University Press Books, 2008.

DAVIS, D. A. Battered black women and welfare reform: between a rock and a hard place. Albany: State University of New York Press, 2006.

ENDING COMMUNITY Homelessness Coalition (ECHO). Results of 2017 Austin/Travis County Annual Count of People Experiencing Homelessness. Austinecho.org. Disponível em: https://www.austinecho.org/wp-content/ uploads/2019/07/2017-Point-in-Time-Count-Results.pdf. Acesso em: 01 set. 2018.

FANON, F. Wretched of the Earth. Preface by Jean-Paul Sartre; Translated from the French by Constance Farrington. New York: Grove Press, 1963.

FANON, F. A Dying Colonialism / Frantz Fanon; Translated from the French by Haakon Chevalier, with an Introduction by Adolfo Gilly. 1st Evergreen ed. New York: Grove Press, 1968. 


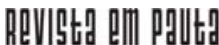

\} "ZONAS DE NÃO SER" - SMITH, C.; MACHICOTE, M. \}

DOI: $10.12957 /$ REP.2020.52017

FLORIDA, M.; MELLANDER, C. The Geography of Economic Segregation in America's Metros, 2015. Disponível em: http://martinprosperity.org/ media/Segregated\%20City.pdf. Acesso em: 02 set. 2018.

HARRISON, F. V. Outsider within: reworking anthropology in the global age. Urbana: University of Illinois Press, 2008.

HOUSTON, O. Austin's "1928 Master Plan" Unleashed Forces Which Still Shape Austin Today, 2018. Disponível em: https://www.austintexas.gov/ sites/default/files/files/City-Council/Houston/CM_OH_1928_Op-Ed.pdf. Acesso em: 10 ago. 2018.

JACKSON, J. Whiteness, Groceries, And Black Women's (Hyper)(In)Visibility - Watercoolerconvos. [online] WaterCoolerConvos, 2015. Disponível em: https://watercoolerconvos.com/2015/10/01/whiteness-groceries-and-blackwomens-hyperinvisibility/. Acesso em: 22 ago. 2018.

KAWASH, S. Terrorists and vampires: Fanon's spectral violence of decolonization. In: ALESSANDRINI, A. C. (Ed.). Frantz Fanon: critical perspectives. New York: Routledge, 1999.

KOBAYASHI, A.; PEAKE, L. Unnatural discourse. 'Race' and gender in geography. Gender, Place \& Culture, 1:2, p. 225-243, 1994. Disponível em: https://www.tandfonline.com/doi/abs/10.1080/09663699408721211. Acesso em: 02 jul. 2020.

MBEMBE, J.-A. Critique of black reason. Durham: Duke University Press, 2017.

MBEMBE, J.-A.; MEINTJES, L. Necropolitics. Public Culture, v. 15, n. 1, 2003.

MCKITTRICK, K. Demonic grounds: black women and the cartographies of struggle. Minneapolis: University of Minnesota Press, 2006.

MCCLAURIN, I. Black Feminist Anthropolog: Theory, Politics, Praxis, and Poetics. Edited by Irma McClaurin. New Brunswick, N.J: Rutgers University Press, 2001.

MULLINGS, L. On our own terms: race, class and gender in the lives of African American women. New York: Routledge, 1997.

O'NEILL, B. Cast aside: boredom, downward mobility and homelessness in post-communist Bucharest. Cultural Anthropology, v. 29, n. 1, 2014.

PERRY, K.-K. Y. Black women against the land grab: the fight for racial justice in Brazil. Minneapolis: University of Minnesota Press, 2013.

PERRY, K.K. Y. Black women and state-sanctioned violence in the brazilian city. International Journal of Urban and Regional Research (IJURR). Disponível em: http://www.ijurr.org/spotlight-on-overview/race-justice-and-thecity/perry/. Acesso em: 2017. 


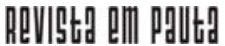

\} "ZONAS DE NÃO SER" - SMITH, C.; MACHICOTE, M. \}

DOI: $10.12957 /$ REP.2020.52017

PIERRE, J. The predicament of blackness: postcolonial Ghana and the politics of race. Chicago: The University of Chicago Press, 2013.

RAHIER, J. M. Blackness in the Andes: ethnographic vignettes of cultural politics in the time of multiculturalism. New York: Palgrave Macmillan, 2014.

SALVATION ARMY. Annual report Austin metropolitan area command. 2016. Disponível em: http://salvationarmyaustin.org/wpcontent/uploads/ sites/6/2016/04/SA_Report_2016down.pdf. Acesso em: 1 out. 2018.

SMITH, C. Blackness, citizenship, and the transnational vertigo of violence in the Americas",. American Anthropologist 117(2):384-387, 2015.

TANG, E. Outlier: the case of Austin's declining african american population. Texas: Institute for Urban Policy Research and Analysis at the University of Texas at Austin, 2014. Disponível em: https://utexas.app.box.com/s/ 16jxum1wmrlumjdi94j9ffsma1skctoy. Acesso em: 02 jul 2020.

TANG, E.; FALOLA, B. Those who left: Austin's declining african american population. Texas: Institute for Urban Policy Research and Analysis at the University of Texas at Austin, 2016.

THOMAS, D. A. Modern blackness: nationalism, globalization and the politics of culture in Jamaica. Latin America otherwise. Durham: Duke University Press, 2004.

THOMAS, D. A. Exceptional violence: embodied citizenship in transnational Jamaica. Durham: Duke University Press, 2011.

WILLIAMS, E.L. Sex Tourism in Bahia Ambiguous Entanglements. Urbana, Illinois: University of Illinois Press, 2013.

DOI: $10.12957 /$ rep.2020.52017

Recebido em 15 de maio de 2020.

Aprovado para publicação em 11 de junho de 2020.

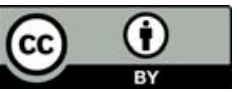

A Revista Em Pauta: Teoria Social e Realidade Contemporânea está licenciada com uma Licença Creative Commons Atribuição 4.0 Internacional. 